
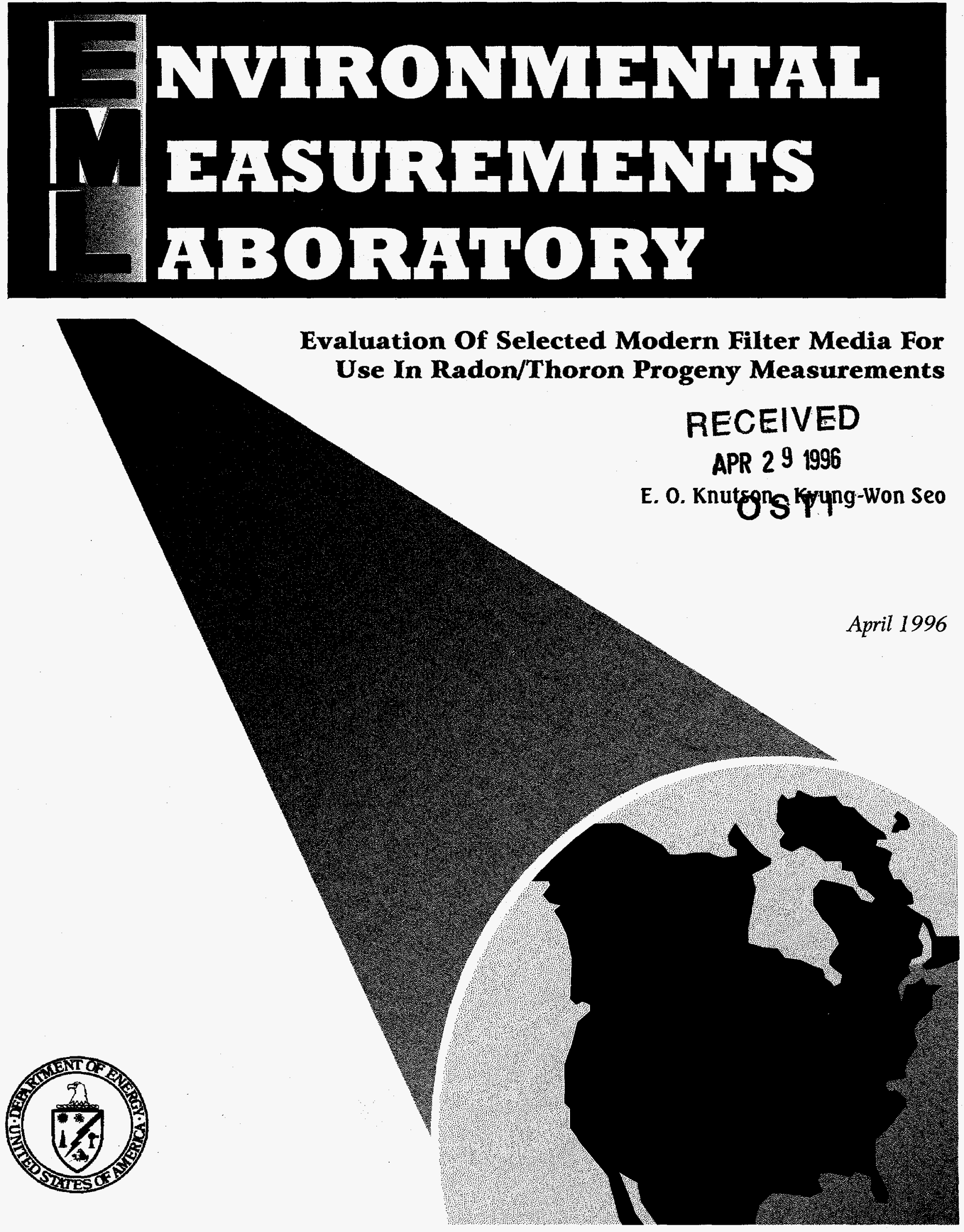


\title{
EVALUATION OF SELECTED MODERN FILTER MEDIA FOR USE IN RADON/THORON PROGENY MEASUREMENTS
}

\author{
Earl. O. Knutson
}

\author{
Environmental Measurements Laboratory \\ U. S. Department of Energy \\ New York, NY 10014-3621 \\ Kyung-Won Seo \\ Health Physics Department \\ Korea Atomic Energy Research Institute
}

April 1996

\section{DISCLAIMER}

"This report was prepared as an account of work sponsored by a agency of the United States Government. Neither the United States Government nor any agency thereof, nor any of their employees, makes any warranty, express or implied, or assumes any legal liability or responsibility for the accuracy, completeness, or usefulness of any information, apparatus, product, or process disclosed, or represents that its use would not infringe privately owned rights. Reference herein to any specific commercial product, process or service by trade name, trademark, manufacturer, or otherwise, does not necessarily constitute or imply its endorsement, recommendation, or favoring by the United States Government or any agency thereof. The views and opinions of authors expressed herein do not necessarily state or reflect those of the United States Government or any agency thereof"

This report has been reproduced directly from the best available copy.

Available from the National Technical Information Services, U. S. Department of Commerce, 5285 Port Royal Road, Springfield, Virginia 22161. 
We tested a number of air sampling filters to determine their suitability for use in radon/thoron progeny measurements. The main test consisted of sampling a radon progeny atmosphere, then measuring the energy spectrum of the alpha particles emerging from the face of the filter. It was found that Millipore AA, long a favorite for this application, is still a good choice. However, this filter is prone to developing electrostatic charge, which can cause the additional collection of ${ }^{218} \mathrm{Po}$ during filter handling. Metricel DM-800 is also a good choice, and it is less prone to charging. 


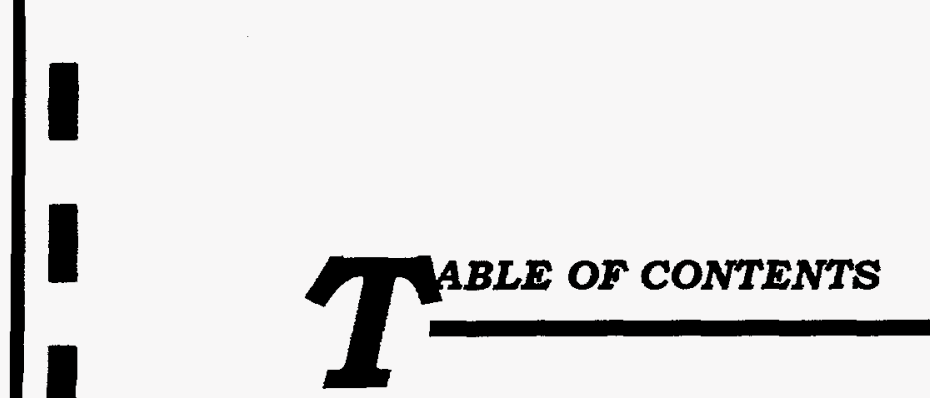

Page

Introduction $\quad \ldots \ldots \ldots \ldots \ldots \ldots \ldots \ldots \ldots \ldots \ldots \ldots \ldots \ldots \ldots \ldots$

Approximate Theory of Energy Spectral shape $\ldots \ldots \ldots \ldots \ldots \ldots \ldots$

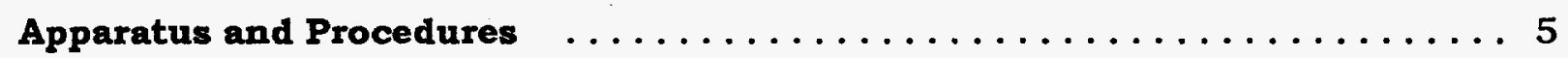

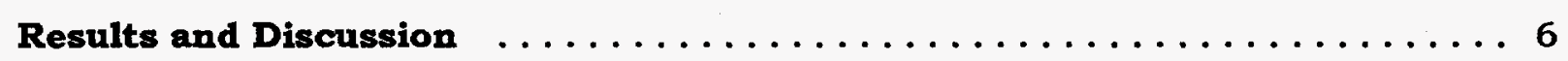

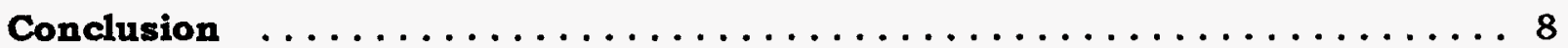

Acknowledgements $\ldots \ldots \ldots \ldots \ldots \ldots \ldots \ldots \ldots \ldots \ldots \ldots \ldots \ldots \ldots$

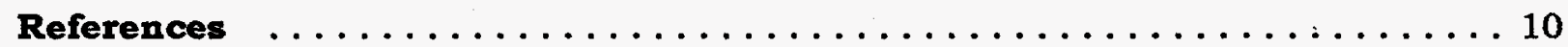

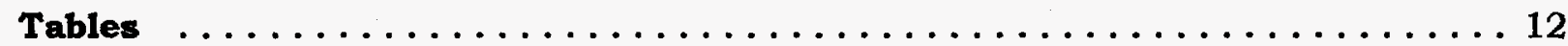

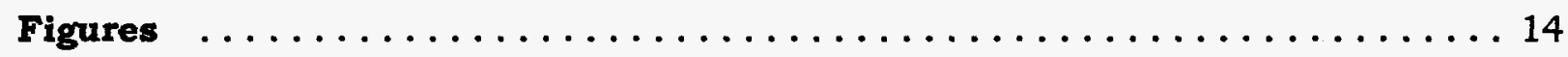




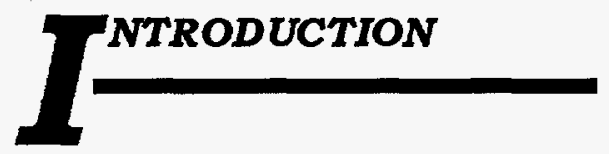

Busigin et al. (1980) discussed the special requirements for air sampling filters that are used for measuring the concentration of radon or thoron progeny. They summarized the data available in the literature, and presented additional data from their own experiments. The purpose of the present work is to report what we have done to complement the information available in Busigin et al. (1980).

For general information on the availability and properties of filters, see the extensive data tables in Liu et al. (1983) or Lippmann (1989).

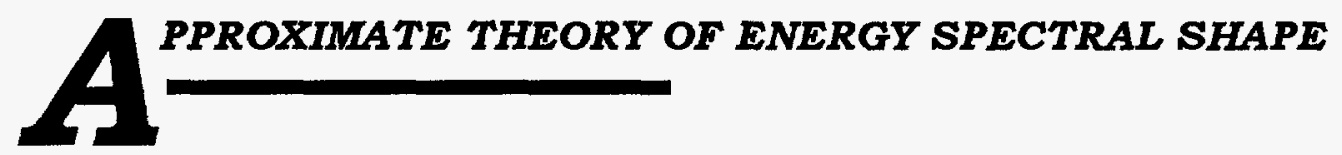

As noted by Busigin et al. (1980), filters which collect aerosol particles in a thin layer on, or close to, the front surface yield narrow energy spectra for the alpha particles from the deposit. Conversely, if the aerosol particles lodge inside the filter, some of the emerging alpha particles will lose energy by intersecting the solid material of the filter, yielding a broader energy spectrum. Typically, this produces a distinctive "tail" on the low energy side of the spectral peak.

Tailing has been studied in other contexts. Bland (1984) used Monte Carlo techniques to compute energy spectral shapes for alpha sources in which the emitting nuclide is distributed uniformly in a solid matrix. He found that the spectra thus calculated could be fitted by a four-parameter function. Westmeier (1984) studied the peak tailing from the decay of ${ }^{224} \mathrm{Ra}$ that has been recoil-implanted into a stainless steel substrate. The key step, which was a Monte Carlo technique, was to calculate the distribution of implantation depths. Westmeier indicated that the depth distribution so derived, most of which could be fitted by a single exponential function, predicted an alpha energy spectral shape in reasonable agreement to that observed. 
We present two simple calculations to show the expected energy distribution of alpha particles originating from radon/thoron progeny deposited in a filter. Assuming for simplicity that the aerosol to be sampled is monodisperse, aerosol filtration theory (Hinds, 1982) shows that the aerosol concentration decreases exponentially with the depth of the penetration into the filter. It follows that the probability distribution of $Y$, where $\mathrm{Y}$ is the depth to which a given particle has penetrated, is given by:

$$
P(Y<y)=\left(1-e^{-\mu y}\right) / C ; \quad 0 \leq y \leq t
$$

where $\mu$ is a function of filter type, air velocity, and particle size; $t$ is the thickness of the filter; and $C=\left(1-e^{-\mu t}\right)$ is the collection efficiency of the filter.

After sampling, we assume that the filter is placed face-to-face with the detector in the vacuum chamber of an alpha spectrometry system. In the first model, we assume that only those alpha particles emitted nearly perpendicular to the filter will reach the detector. In this case, the probability distribution of $\mathrm{L}$, where $\mathrm{L}$ is the distance traveled by the alpha particle before exiting the filter medium, is the same as the probability distribution of Y:

$$
\mathrm{P}(\mathrm{L}<l)=\mathrm{P}(\mathrm{Y}<l)=\left(1-\mathrm{e}^{-\mu \mathrm{X}}\right) / \mathrm{C}
$$

where $\mathrm{X}$ is the smaller of $\mathrm{t}$ and $l$. The corresponding probability density, obtained by differentiating Eq. 2, is:

$$
\begin{aligned}
\mathrm{p}(l) & =\mu \mathrm{e}^{-\mu l} / \mathrm{C} & & \text { for } 0 \leq l \leq \mathrm{t} \\
& =0 & & \text { otherwise }
\end{aligned}
$$

The peak is at $l=0$, and the probability density drops exponentially with $l$. Since the energy loss is closely related to $l$, Eq. 3 also gives an indication of the energy spectrum of detected alpha particles. However, $l=0$ would correspond to the highest energy, and $l>0$ to smaller energies. 
In the second model, we consider the case where the detector is larger than the filter and the filter is placed very close to the detector. Potentially, this will allow detection of all alphas emitted into the forward hemisphere. Consider an alpha emitted at an angle $\Theta$ from the perpendicular, and from a depth $y$ within the filter. To exit the filter, it must travel a path length $l=y / \cos \Theta$. Given that emission is in the forward direction, the probability of $\Theta$ in the range $\theta$ to $\Theta+d \Theta$ is $\sin \Theta$, and the probability distribution of $y$ has already been given. To calculate $P(L<l)$, it is necessary to integrate probabilities over that part of the $y, \Theta$ plane which satisfies the conditions $\cos \Theta>y / l$ and $y<t$. The result is:

$$
P(L<l)=\frac{1-e^{-\mu X}}{C}-\frac{1-e^{-\mu X}(1+\mu X)}{C \mu l}
$$

The first term on the right is the same as in Eq. 2 (corresponding to $\Theta=0$ ), so the second term gives the effect of alphas emitted with $0<\theta<\pi / 2$. The probability density corresponding to Eq. 4 is:

$$
p(l)=\frac{l-e^{-\mu X}(1+\mu X)}{C \mu l^{2}}
$$

In applying these equations, it is convenient to measure both $l$ and $t$ in terms of areal density. Taking Metricel DM-800 (Gelman Scientific Co., Ann Arbor, MI) as an example, we measured a thickness of $44 \mathrm{~g} \mathrm{~m}^{-2}$, and Liu et al. found that the collection efficiency $\mathrm{C}$ exceeds $99.99 \%$ for all air velocities and particle sizes tested, which implies that $\mu$ exceeds $0.21 \mathrm{~m}^{2} \mathrm{~g}^{-1}$. We will use $\mathrm{t}=50 \mathrm{~g} \mathrm{~m}^{-2}$ and $\mu=0.2 \mathrm{~m}^{2} \mathrm{~g}^{-1}$ to describe a hypothetical high-efficiency membrane filter. 
To convert from path length to alpha particle energy loss, we used the approximation (Stephens and Hurlimann, 1958):

$$
\mathrm{R}=3.9 \mathrm{E}^{3 / 2}
$$

in which $\mathrm{R}$ is the alpha particle range in $\mathrm{g} \mathrm{m}^{-2}$ and $\mathrm{E}$ is the energy in $\mathrm{MeV}$. As applied to air at $15^{\circ} \mathrm{C}$ and $101.3 \mathrm{kPa}$, this equation fits range data within $10 \%$ from 4 to 8 $\mathrm{MeV}$. Because common filter materials (e.g. cellulose acetate, cellulose nitrate) have an electrons/mass ratio of similar to that of air, we assume that Eq. 6 also applies to filters. Bland (1984) used a similar range-energy expression.

Figure 1 shows Eqs. 3 and 5, plotted for the hypothetical high-efficiency filter and an alpha decay energy of $7.7 \mathrm{MeV}$. The characteristic shape, with the steep right side and the tailing to the left side, is clearly seen. The full width a half maximum (FWHM) is about 200 and $300 \mathrm{keV}$ for the curves of Eqs. 3 and 5, respectively.

In practice, other factors would change the shape of these spectra. First, the somewhat randomly placed void spaces within filters means that the energy lost by a emerging alpha particle is a stochastic function of the path length; this will blur the observed energy spectrum. Second, the inert layer covering the alpha detector's sensitive volume will cause further tailing, depending on the alpha particle's angle of approach (Kruppa and Kurzak, 1991). Third, electronic noise would cause the spectra to blur slightly, particularly in the area of the peak.

The value $7.7 \mathrm{MeV}$ in the above example is the energy of an alpha particle from ${ }^{214} \mathrm{Po}$. In order to avoid complications in analyzing radon progeny samples, it is important that the tail from the $7.7 \mathrm{MeV}$ peak does not extend below $6.0 \mathrm{MeV}$, the energy of the ${ }^{218} \mathrm{Po}$ alpha. It is seen in Figure 1 that the curve for solid angle $=0$ meets this criterion, but the other curve extends slightly below $6.0 \mathrm{MeV}$. 


\section{PPARATUS AND PROCEDURES}

The filter types that were studied in the present work are listed in Table 1. Although there is some overlap, most filters were selected to complement the filter types studied by Busigin et al. (1980).

The filter thickness $\left(\mathrm{g} \mathrm{m}^{-2}\right)$ was determined by weighing a sample filter using a common analytical balance and dividing by the area of the filter. No special humidity conditioning of the filters was done. In a few cases, the background alpha particle count rate was determined by placing clean filters into a drawer type gross alpha scintillation counter ( $\mathrm{Tu}, 1992)$. Alpha particle background is an important consideration when sampling radon progeny at low concentrations.

The pressure drop of each filter type was measured at two flow rates using a flow train consisting of a Gilibrator (Gilian Instrument Company, Wayne, $\mathrm{NJ}$ ), the filter holder, a Heise 0-800 $\mathrm{mm} \mathrm{Hg}$ absolute pressure gauge, a rotometer-type flow meter, and a suction pump. Flow rates, measured by the Gilibrator, were approximately $5 \mathrm{Lpm}$ and (when possible) $25 \mathrm{Lpm}$. (When $25 \mathrm{Lpm}$ was not achievable, we used the highest flow we could achieve.) The corresponding air velocities at the filter face were 7.8 to $39 \mathrm{~cm} \mathrm{~s}^{-1}$.

To test the suitability of the filters for alpha spectrometry, air samples were taken from one of two points in the EML Radon, Thoron and Progeny Exposure Facility (Fisenne and George, 1992). One sampling point was the filtered, radon-laden air stream just downstream of the radon source. In this case, the progeny consisted almost entirely of unattached ${ }^{218} \mathrm{Po}$. The sampling time and flow rate were $2 \mathrm{~min}$ and $5 \mathrm{~L} \mathrm{~min}{ }^{-1}$, respectively. The other sampling point was the radon chamber proper, in which the aerosol concentration usually exceeded $10,000 \mathrm{~cm}^{-3}$. Here the progeny consisted of a mixture of ${ }^{218} \mathrm{Po},{ }^{214} \mathrm{~Pb},{ }^{214} \mathrm{Bi},{ }^{214} \mathrm{Po}$, and were mostly attached to aerosol particles. Two flow rates, $5 \mathrm{Lpm}$ and (where possible) $25 \mathrm{Lpm}$, were used and the sampling time was $5 \mathrm{~min}$. 
After sampling, the filters were placed into the alpha spectrometer (Model 256A, Tenelec Corp., TN). A Canberra Model 20 multichannel analyzer was used to record pulses in 2048 channels, each with an energy width of $3190 \mathrm{eV}$. After counting for $2000 \mathrm{~s}$, the data from two regions of interest (corresponding to ${ }^{218} \mathrm{Po}$ and ${ }^{214} \mathrm{Po}$ alpha particles) were transferred to a personal computer and stored on a floppy disk for further analysis, discussed below.

This work was done in accordance with the quality assurance principles and practices described by Feely (1992).

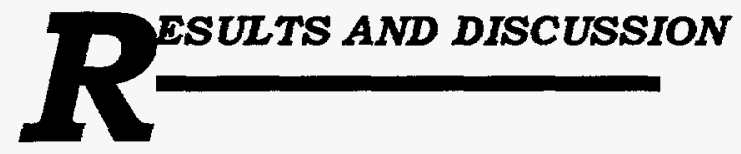

Shown in Table 1 are the key physical characteristics of the tested filters. Note that the thickest of the filters tested has a thickness about equal to the range of $a^{214} \mathrm{Po}$ alpha particle, $84 \mathrm{~g} \mathrm{~m}^{-2}$.

Also shown in Table 1 is the filter pressure drop at $25 \mathrm{~cm} \mathrm{~s}^{-1}$, which is a common face velocity for sampling radon progeny. The tabulated value was derived by log-log interpolation from our two measured values. Another column in the table shows that the slope of these log-log interpolations was generally near unity. Shown for comparison are a few values from the tables given by Liu et al. (1983).

Figure 2 shows the pulse height spectrum of ${ }^{214} \mathrm{Po}$ alpha particles derived from sampling unattached ${ }^{218}$ Po onto a Nuclepore filter. The peak is narrow, and the low energy tail is virtually nonexistent. Clearly, there is very little penetration of ${ }^{218}$ Po into this filter. The peak width, measured by the FWHM, is only $32 \mathrm{keV}$, and is probably due to a combination of electronic noise and (variable) energy loss in the inert layer on the alpha detector. This demonstrates that the level of electronic noise in the alpha spectrometer is quite low. 
Shown in Table 2 are values of FWHM from the ${ }^{214} \mathrm{Po}$ alpha particles in the various tests. In order to avoid excessive statistical scatter, results were included only if at least one channel had 25 or more counts. The values given in the table are the number of channels with counts exceeding one-half of the counts in the peak channel. To convert the number of channels to energy, multiply by $3.19 \mathrm{keV}$. Also shown in Table 2 are the full widths at quarter maximum and eight maximum. Together, the three full widths give a better description of the low energy tail than FWHM does alone.

As seen in Table 2, the FWHM for unattached ${ }^{214}$ Po is quite small (from 6 to 15 channels, or 20 to $50 \mathrm{keV}$ ) regardless of filter type. Statistical fluctuations probably account for part of this spread. This was expected, since unattached ${ }^{218}$ Po is a highly diffusive species that will collect near the surface of the filter, regardless of filter type. Regarding ${ }^{214} \mathrm{Po}$ alphas from attached progeny, Table 2 gives a surprising result: with one exception, the FWHM is not significantly larger than for the same alpha from unattached progeny. The differences between that attached and unattached samples are seen more clearly in the width at one-quarter and one-eight maximum.

Jonassen and McLaughlin (1976) discussed a phenomenon that could explain the surprising result mentioned above. They found that the alpha detector may become contaminated by ${ }^{214} \mathrm{~Pb}$ atoms recoiling off the filter from earlier decays of ${ }^{218} \mathrm{Po}$. Thus, some ${ }^{214} \mathrm{Po}$ alphas may come directly from the surface of the detector, yielding an artificially narrow pulse spectrum. Another possible reason for the narrow alpha peak is that our attached progeny samples may have contained a significant amount of unattached ${ }^{218}$ Po.

Our data do not permit us to select between the two mechanisms just mentioned, but an insight can be gained by examining the energy spectrum from ${ }^{218} \mathrm{Po}$ alpha particles. (We have concentrated on results from ${ }^{214} \mathrm{Po}$ because, in most cases, the number of counts was higher for ${ }^{214} \mathrm{Po}$ than $\left.{ }^{218} \mathrm{Po}\right)$. For those tests in which both ${ }^{218} \mathrm{Po}$ and ${ }^{214}$ Po alphas had peak-channel counts exceeding 25 , both alpha peaks appeared to have the same width. Since recoil cannot be a factor for ${ }^{218} \mathrm{Po}$, there is an implication that recoil is not involved in the ${ }^{214}$ Po result either. 
It is seen in Table 2 that Metricel DM- 800 has the largest FWHM of the filters measured. Figure 3 shows the ${ }^{214}$ Po alpha spectrum from the high flow rate test. The similarity to theory (Figure 1 ) is obvious. However, the observed FWHM is about 110 $\mathrm{keV}$, implying a value of $\mu$ about 0.5 , as compared to 0.2 in the Figure 1 calculation. Since Figure 3 shows very little tailing below $6.0 \mathrm{MeV}$, there is no reason not to use this filter for radon progeny sampling.

Only limited comparisons can be made to the results of Busigin et al. (1980) because of their method of presenting results. Their Figure 2, which pertains to unattached progeny, shows a ${ }^{214}$ Po FWHM of about $80 \mathrm{keV}$. For ${ }^{214} \mathrm{Po}$ alphas from a sample of attached progeny, their Figure 3 shows FWHM $=220 \mathrm{keV}$. Both values are larger than any of our results; however, we did not test either of filter types involved in their Figures 2 and 3.

In working with these filters, we found that among the membrane filters, Metricel filters were less likely to acquire electrostatic charge during handling. This can be important because freshly formed ${ }^{218} \mathrm{Po}$ is known to be electrically charged, and in some environments, this charge may persist for many tens of seconds. Filters that become charged from mere handling can collect a substantial amount of ${ }^{218}$ Po during transfer from the filter holder to the alpha particle counter, giving an erroneous high result for ${ }^{218} \mathrm{Po}$. Although this is not a common problem, we have encountered it in two different field trips. Metricel filters are clearly better in this situation.

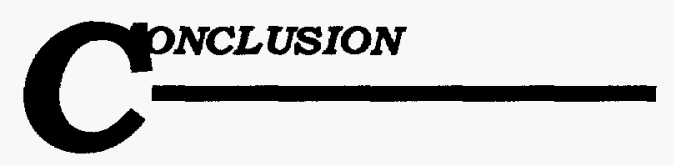

Of the several membrane filter tested, all are acceptable for radon progeny sampling. Millipore AA, which for decades has been a standard in this application, is still a good choice. However, Metricel DM-800 is recommended for those situations where electrostatic charge is a problem. 


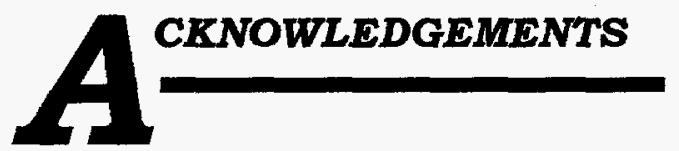

The authors are happy to acknowledge help from: Irwin Haskel of EML's Instrumentation Division, and Patricia Scofield, past member of EML's Radiation Physics Division, for assistance in setting up the alpha spectrometry system; Andreas George of the Radiation Physics Division for help in the sampling aspects; Carl Gogolak, Keng-Wu Tu and Wayne Lowder of the Radiation Physics Division, and EML's Technical Editor Nancy Chieco for reading the manuscript and suggesting improvements. 


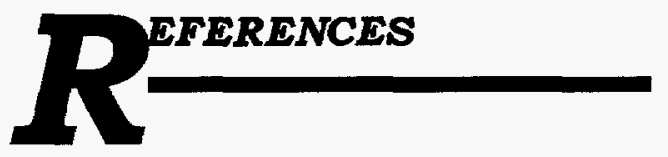

Bland, C. J.

Int. J. Appl. Radiat. Isot., $\underline{35}$, 279-283 (1984)

Busigin, A., A. W. van der Vooren, and C. R., Philips,.

Environ. Sci. Techn., 14, 533-536 (1980)

Feely, H. W.

in: Procedures Manual

Chieco N. A. , D. C. Bogen, and E. O. Knutson, (Editors),

USDOE Report HASL-300, 27th Edition, Vol. I, Section 1 (1992)

Fisenne, I. M. and A. C. George

in: EML Procedures Manual

Chieco, N. A., D. C. Bogen, and E. O. Knutson (Editors)

USDOE HASL-300, 27th Edition, Vol. I, Section 3 (1992)

Hinds, W. C.

Aerosol Technology Wiley-Interscience, New York, NY (1982)

Jonassen, N. and J. P. McLaughlin

J. Aerosol Sci., 7, 141-150 (1976)

Kruppa, R. J. and K. Kurzak

Nucl. Instum. Meth., A307, 469-483 (1991)

Lippmann, M.

in: Air Sampling Instruments for Evaluation of Atmospheric Contaminants, Chapter 0 Hering S. V. (Editor)

American Conference of Government Industrial Hygienists, Cincinnati, OH (1989)

Liu, B. Y. H., D. Y. H. Pui, and K. L. Rubow

Aerosols in the Mining and Industrial Work Environment, Chapter 70

Marple V. A. and B. Y. H. Liu (Editors)

Ann Arbor Science Publishers, Ann Arbor MI (1983) 
Stephens, W. E. and T. Hurlimann.

Handbook of Physics, Chapter 4 of Part 9

Condon, E. U. and H. Odeshaw (Editors)

McGraw-Hill, New York, NY (1958)

Tu, K. W.

Personal communication, USDOE Environmental Measurements Laboratory (1992)

Westmeier, W.

Int. J. Appl. Radiat. Isot., $\underline{35}$, 263-270 (1984) 
TABLE 1

KEY PROPERTIES OF THE FILTERS SELECTED FOR STUDY

\begin{tabular}{|c|c|c|c|c|c|c|}
\hline & & Alpha & & & & \\
\hline Filter type & Thickness & bkgd $^{e}$ & & low re & $\operatorname{stance} e^{f}$ & \\
\hline & $\left(\mathrm{g} \mathrm{m}^{-2}\right)$ & $(\mathrm{cpm} / 2 \pi)$ & $\mathbf{A}$ & B & C & D \\
\hline Millipore $\mathbf{A A}^{\mathbf{a}}$ & 44 & & 7.9 & 1.12 & 9.1 & 1.07 \\
\hline$\propto \quad \Rightarrow D V^{a}$ & 82 & & 14.0 & 1.11 & & \\
\hline$\propto \quad \Rightarrow H V^{a}$ & 79 & & 37.2 & 1.17 & & \\
\hline Metricel DM- $800^{\mathrm{b}}$ & 44 & 0.11 & 10.1 & 1.10 & 13.59 & 1.04 \\
\hline$“ \quad \Rightarrow \mathrm{DM}-450^{\mathrm{c}}$ & 32 & 0.11 & 23.6 & 1.12 & & \\
\hline$\star \quad " \mathbf{G N}^{\mathrm{b}}$ & 33 & 0.07 & 8.1 & 1.18 & & \\
\hline Versapor $0.8^{\mathrm{b}}$ & 85 & & 9.8 & 1.13 & & \\
\hline$" \quad=0.45^{\mathrm{b}}$ & 85 & & 18.5 & 1.15 & & \\
\hline Nuclepore $0.8^{c}$ & 8.6 & & 19.6 & 1.46 & & \\
\hline $934 A H^{d}$ & 66 & 2.6 & 1.10 & 2.8 & 1.07 & \\
\hline Whatman $\# 41^{\mathrm{d}}$ & 79 & 3.0 & 1.27 & 2.2 & 1.12 & \\
\hline Spectro Grade ${ }^{b}$ & 83 & & 2.5 & 1.14 & 2.1 & 1.03 \\
\hline
\end{tabular}

${ }^{a}$ Millipore Corp., Bedford, MA.

${ }^{b}$ Gelman Scientific Co., Ann Arbor, MI.

${ }^{\mathrm{C}}$ Nuclepore Corp., Pleasanton, CA.

${ }^{\mathrm{d}}$ Whatman Reeve Angel, Clifton, NJ.

${ }^{\mathrm{e}}$ For a 47-mm diameter filter.

${ }^{\mathrm{r}} \mathrm{A}=$ pressure drop in $\mathrm{kPa}$ at face velocity, $\mathrm{v},=25 \mathrm{~cm} \mathrm{~s}^{-1}$.

$B=$ exponent in expression; $p=$ const. $v^{B}$.

C, D = same as A, B but based on data from Liu et al. (1983). 
TABLE 2

WIDTHS OF THE PEAK IN THE ENERGY SPECTRA OF ${ }^{214}$ Po ALPHA PARTICLES FROM SELECTED FILTER MEDIA ${ }^{a}$

\begin{tabular}{|c|c|c|c|c|c|c|c|c|c|}
\hline & \multicolumn{3}{|c|}{$\begin{array}{l}\text { Unattached, } \\
\text { low velocity }\end{array}$} & \multicolumn{3}{|c|}{$\begin{array}{l}\text { Attached, } \\
\text { low velocity }\end{array}$} & \multicolumn{3}{|c|}{$\begin{array}{c}\text { Attached, } \\
\text { high velocity }\end{array}$} \\
\hline & $1 / 2$ & $1 / 4$ & $1 / 8$ & $1 / 2$ & $1 / 4$ & $1 / 8$ & $1 / 2$ & $1 / 4$ & $1 / 8$ \\
\hline Millipore AA & 11 & 17 & 27 & - & - & - & $\#$ & \# & $\#$ \\
\hline Millipore DV & 10 & 15 & 25 & - & - & - & 11 & 39 & 105 \\
\hline Millipore HV & 9 & 16 & 30 & 10 & 21 & 41 & 12 & 22 & 43 \\
\hline Metricel DM-800 & - & - & - & 30 & 54 & 91 & 34 & 62 & 83 \\
\hline Metricel DM-450 & 6 & 18 & 35 & 15 & 29 & 39 & 18 & 34 & 48 \\
\hline Metricel GN & 8 & 19 & 23 & - & - & - & * & * & * \\
\hline Versapor 0.8 & 15 & 28 & 45 & 6 & 36 & 73 & 18 & 49 & 81 \\
\hline Versapor 0.45 & 13 & 16 & 31 & 15 & 27 & 49 & 15 & 31 & 56 \\
\hline Nuclepore 0.8 & 10 & 16 & 25 & - & - & - & * & * & * \\
\hline 934AH & 9 & 19 & 30 & - & - & - & * & * & * \\
\hline Whatman \#41 & 7 & 15 & 24 & - & - & - & * & * & * \\
\hline Spectro Grade & 11 & 20 & 39 & - & - & - & * & * & * \\
\hline
\end{tabular}

${ }^{a}$ Full width (in number of channels) at $1 / 2,1 / 4$ and $1 / 8$ of maximum.

- = insufficient counts.

* $=$ not tested.

\# = data lost. 


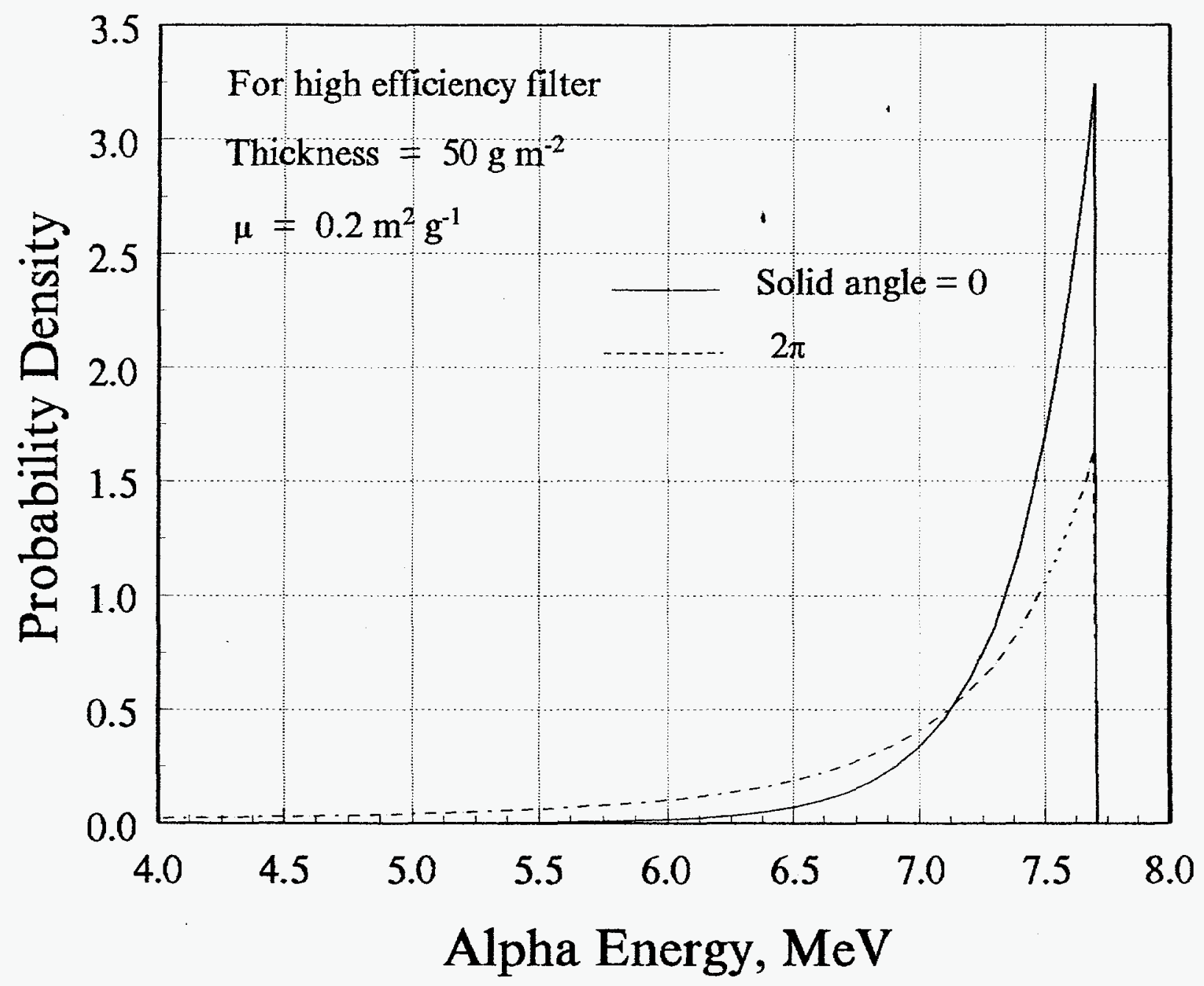

Figure 1. Theoretical energy spectrum of alpha particles from aerosols deposited on a hypothetical high efficiency filter. 


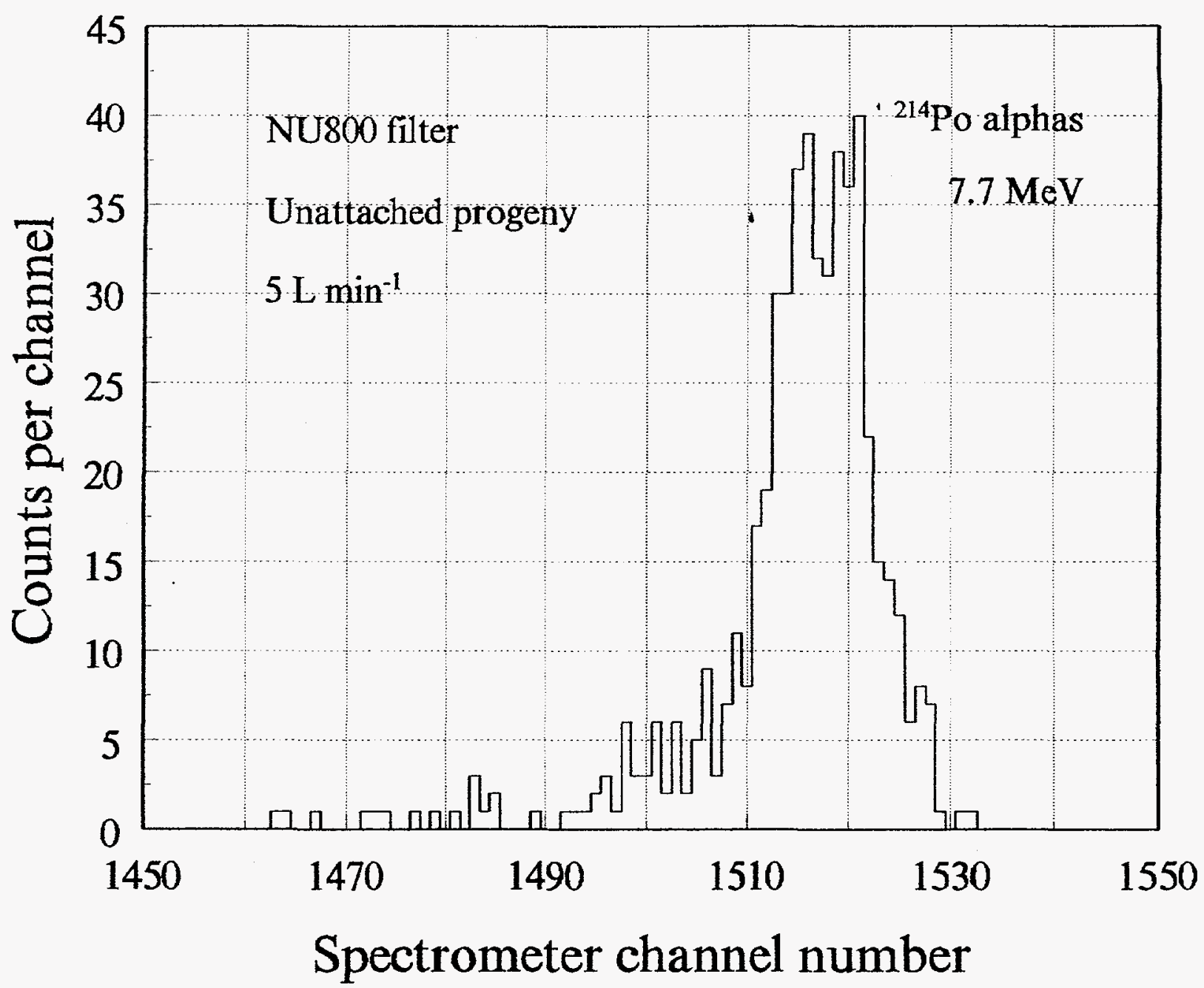

Figure 2. Measured energy spectrum of alpha particles from ultrafine aerosols deposited on a Nuclepore filter. 


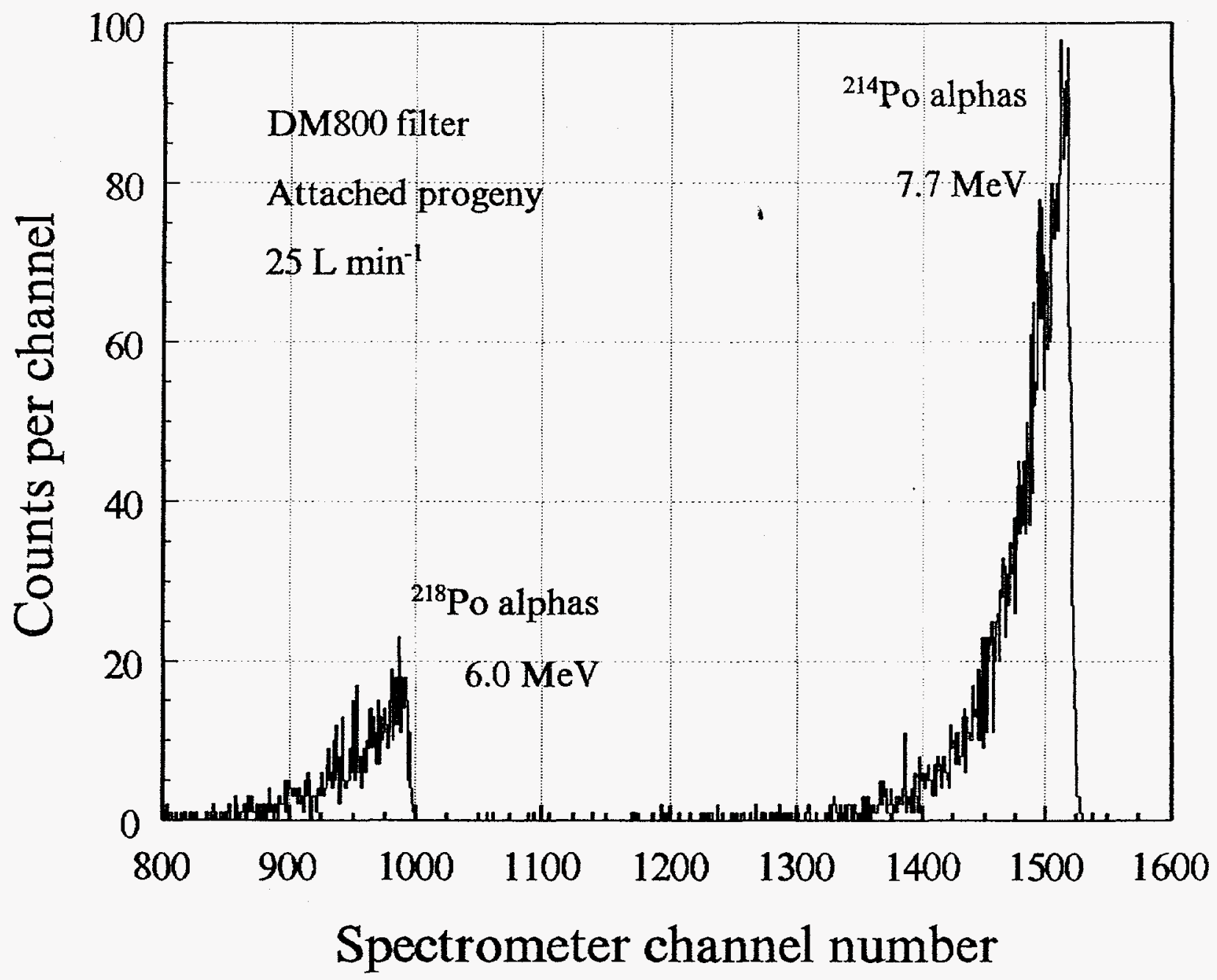

Figure 3. Measured energy spectrum of alpha particles from aerosols deposited on a Metricel filter. 